\title{
Monophasic Synovial Sarcoma of the Lower Eyelid: Rare Tumor involving Rare Site
}

\author{
${ }^{1}$ Azeem Mohiyuddin, ${ }^{2}$ A Sagayaraj, ${ }^{3}$ TR Harshita, ${ }^{4}$ TN Suresh
}

\section{ABSTRACT}

Aim: Synovial sarcoma of eyelid is extremely rare. We are reporting a case of massive synovial sarcoma of lower eyelid extending to soft tissues over the anterior wall of maxilla.

Case report: A 58-year-old male patient presented with a large mass involving the left lower eyelid and extending over the soft tissues of the anterior wall of the maxilla since 15 years. Clinical examination showed a firm soft tissue mass measuring $16 \times 8 \times 6 \mathrm{~cm}$ involving the left lower eyelid and extending to soft tissues over the maxilla. The mass showed ulceration and was bleeding on touch.

Computed tomography scan showed an exophytic lobulated heterogeneously enhancing mass lesion with intense enhancing capsule measuring $14 \times 9.3 \times 8.4 \mathrm{~cm}$ with few internal areas of necrosis arising from left preseptal region. The lesion was causing erosion at the medial wall and floor of left orbit.

It was clinically diagnosed as hemangiopericytoma. The patient was taken up for surgery and wide excision of the tumor and medial maxillectomy was done. The defect was reconstructed with a glabellar flap.

Keywords: Immunohistochemistry, Lower eyelid, Monophasic synovial sarcoma.

How to cite this article: Mohiyuddin A, Sagayaraj A, Harshita TR, Suresh TN. Monophasic Synovial Sarcoma of the Lower Eyelid: Rare Tumor involving Rare Site. Int J Head Neck Surg 2015;6(4):190-192.

Source of support: Nil

Conflict of interest: None

\section{INTRODUCTION}

Synovial sarcomas are rare and account for $5 \%$ of all soft tissue sarcomas. Six to $8 \%$ of synovial sarcomas occur in head and neck. ${ }^{1}$ They are known as synovial sarcoma

\footnotetext{
${ }^{1}$ Professor and Head, ${ }^{2}$ Associate Professor, ${ }^{3}$ Senior Resident ${ }^{4}$ Professor

1,2Department of Otolaryngology and Head and Neck Surgery Sri Devaraj Urs Medical College, Kolar, Karnataka, India

${ }^{3}$ Department of ENT, Sri Devaraj Urs Medical College, Kolar Karnataka, India

${ }^{4}$ Department of Pathology, Sri Devaraj Urs Medical College
} Kolar, Karnataka, India

Corresponding Author: Azeem Mohiyuddin, Professor and Head, Department of Otolaryngology and Head and Neck Surgery, Sri Devaraj Urs Medical College, Kolar, Karnataka India Phone: +919845373279, e-mail: azeem.mohiyuddin@gmail.com because they histologically resemble synovium but are known to arise from pluripotent mesenchymal cells. ${ }^{2}$ Here we report one such rare case of monophasic synovial sarcoma arising from the lower eyelid.

\section{CASE REPORT}

A 58-year-old male patient presented to our outpatient department with swelling arising in the left lower eyelid and extending over the soft tissues of the anterior wall of the maxilla. He noticed the swelling in the lower eyelid region 15 years back, which was slow growing and rapidly increased in size in the last 1 year. Clinical examination showed a firm mass with ulceration measuring $16 \times 8 \times 6 \mathrm{~cm}$, involving the left lower eyelid and extending to soft tissues over the maxilla. The mass showed ulceration and was bleeding on touch. The ipsilateral eye was covered with the mass and there was only perception of light in the left eye (Fig. 1).

Computed tomography scan demonstrated exophytic lobulated heterogeneously enhancing mass with intense enhancing capsule measuring $14 \times 9.3 \times 8.4 \mathrm{~cm}$ with few internal areas of necrosis arising from left preseptal region of the lower eyelid. Posteriorly the mass was seen extending into the left orbit. Globe appeared intact but was displaced posteriorly and inferiorly. The lesion was causing erosion at the floor of left orbit, medial wall of maxilla, maxillary sinus, and nasal cavity (Fig. 2).

As the patient had active bleeding on presentation and earlier biopsy had shown hemangioma, clinical diagnosis of hemangiopericytoma was done. The patient underwent

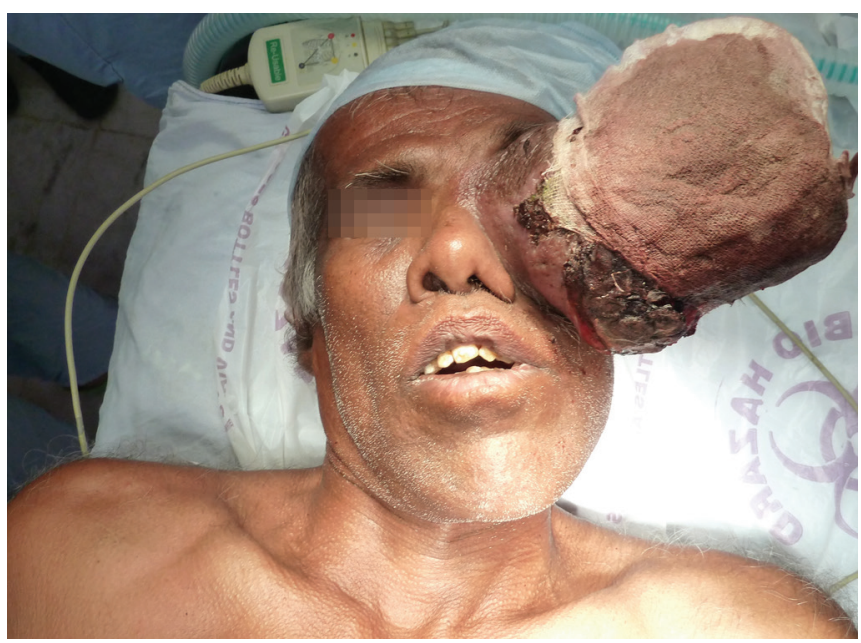

Fig. 1: Preoperative picture showing the tumor 


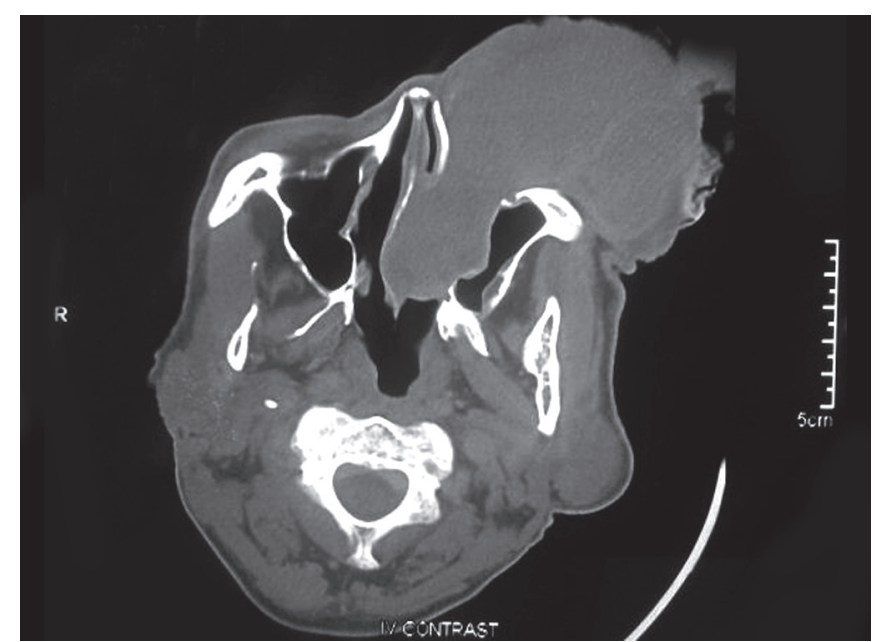

Fig. 2: CT PNS showing heterogeneously enchanting mass lesion arising from left preseptal region from lower eyelid, causing erosion of medial wall and floor of left orbit

wide excision of the tumor and medial maxillectomy. Postoperative defect was reconstructed using a glabellar flap (Fig. 3).

Histopathology showed tumor having both hypocellular and hypercellular areas. The hypercellular component showed spindle to oval-shaped cells arranged in storiform pattern around many capillaries. These cells showed intracytoplasmic vacuoles in some foci. The nucleus was oval to spindle shaped with vesicular chromatin. The hypocellular areas showed hyaline/desmoplastic change. Mitotic activity was sparse. Large arborizing, varied-sized blood vessels were seen within the tumor (Fig. 4).

On immunohistiochemistry, the cells expressed CD 34, CD 99, and bcl2 and were negative for EMA, CK, and CD31.

Diagnosis of monophasic synovial sarcoma was made and adjuvant radiotherapy was advised. However, the patient refused radiotherapy. The patient has been on regular follow-up and is asymptomatic till date.

\section{DISCUSSION}

Synovial sarcoma was first described by Simon in 1865 . The name was first coined by Sabrazes in $1934 .{ }^{3}$ As per World health organization, synovial sarcoma is defined as "Mesenchymal spindle cell tumors" that display various epithelial differentiation, including glandular formation and have a specific chromosomal translocation $t(X ; 18)$ (p11;q11).

Synovial sarcoma is known to arise from undifferentiated or pluripotent mesenchymal cells. Initially it was thought to arise from synovium. ${ }^{5}$ Majority of these tumors are associated with chromosomal translocation between chromosome 18 and $\mathrm{X}$ that results in the fusion of the SYT genes located on chromosome 18 and the SSX-1 or SSX-2 gene on chromosome X. ${ }^{6}$

Synovial sarcomas in head and neck region are rare accounting for 6 to $8 \%$ of all synovial sarcomas. Most

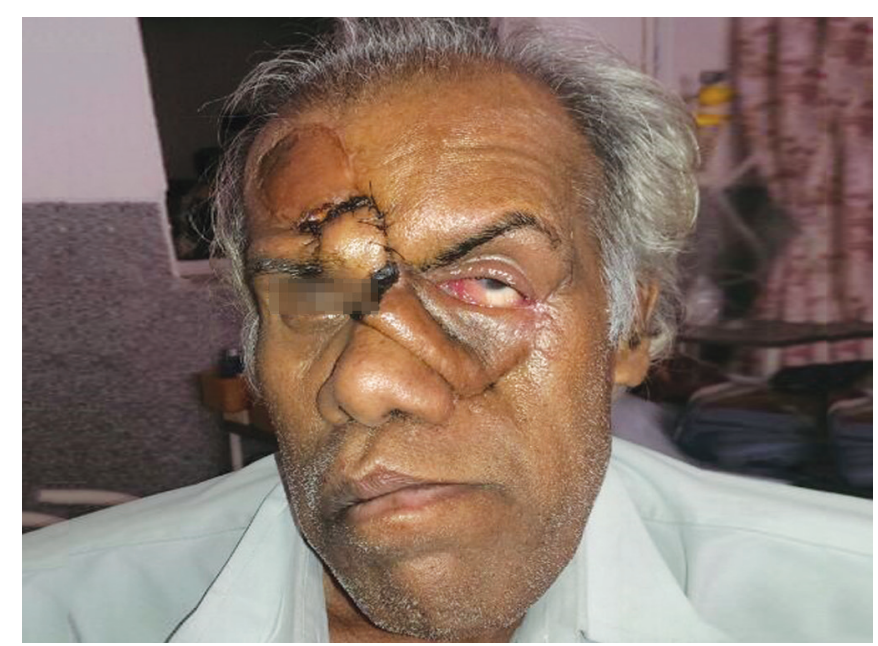

Fig. 3: Postoperative photograph

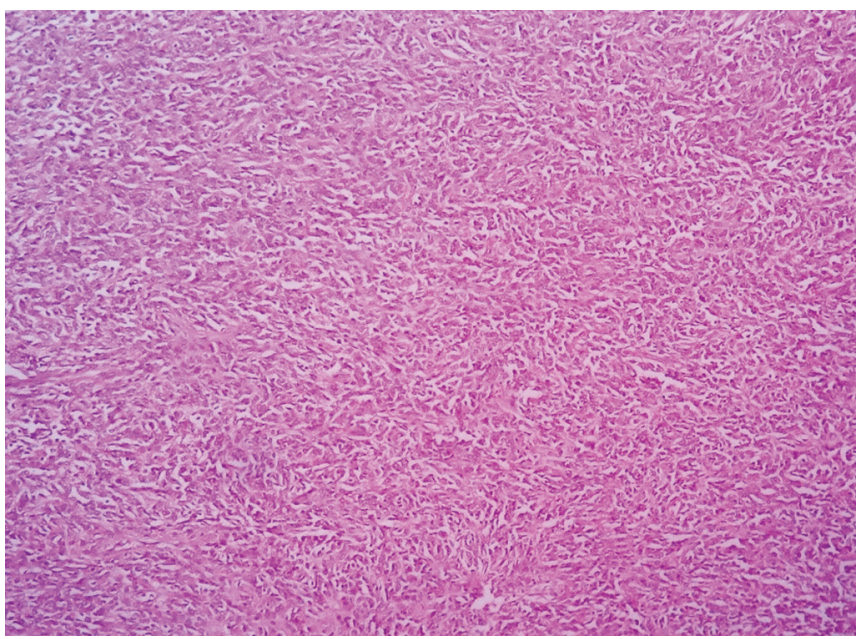

Fig. 4: Histopathology slide showing monophasic synovial sarcoma showing spindle cells arranged in whorled and storiform pattern

common site is the hypopharynx. They are seen more in males aged 15 to 40 years. ${ }^{1-3}$

\section{Types}

- Monophasic epithelial type

- Monophasic spindle cell type

- Biphasic type

- Poorly differentiated type (Enzinger and Weiss). ${ }^{7}$

Immunohistiochemistry helps in differentiating other poorly differentiated sarcomas, neurogenic sarcoma, and hemangiopericytoma. Epithelial components stain positive for cytokeratin and spindle cells stain positive for Vimentin. ${ }^{2,4}$ Synovial sarcomas are also immunoreactive to EMA, S100, Bcl-2, CD 99, and Calponin. But there are no specific or sensitive immunohistochemical markers. ${ }^{8,9}$

Detection of $\mathrm{t}(\mathrm{X} ; 18)(\mathrm{SYT} ; \mathrm{SSX})$ translocation using reverse transcription polymerase chain reaction is diagnostic of synovial sarcoma. Biphasic synovial sarcomas 
commonly show SYT-SSX 1 translocation and monophasic synovial sarcoma is positive for SYT-SSX 2 translocation. ${ }^{5,9}$

Surgery is the mainstay of treatment with adjuvant radiotherapy advocated for high-grade tumors. Head and neck synovial sarcomas are aggressive tumors, but some have better prognosis, probably due to early detection. ${ }^{6}$

Five-year survival rate is around 25 to $55 \%$, with high chances of metastasis to lungs and bones. ${ }^{10}$

\section{CONCLUSION}

Head and neck synovial sarcomas are rare aggressive tumors. Adequate surgical resection followed by radiotherapy remains the mainstay of the treatment.

\section{REFERENCES}

1. Park JK, Ham SY, Hwang JC, Jeong YK, Lee JH, Yang SO, Suh JH, Choi DH. Synovial sarcoma of the head and neck: A case of predominantly cystic mass. AJNR Am J Neuroadiol 2004 Jun-Jul;25(6):1103-1105.

2. Mahesh KT, Ponnuswamy IA, David MP, Shivahare P, Puttaranganayak MI, Sinha P. Synovial sarcoma of the buccal mucosa: A rare case report. Case Rep Dent 2013;2013: 938291.
3. Sabrazes J, Loubat E, de Grially R, Magendie J. Synovia sarcoma. Gazette Hebdomadaire de Science M'edicale de Bordeaux 1934;55:754-762.

4. Agarwal AP, Shet TM, Joshi R, Desai SB, Chinoy RF. Monophasic synovial sarcoma of tongue. Indian J Pathol Microbiol 2009 Oct;52(4):568-570.

5. Rigante M, Visocchi M, Petrone G, Mule A, Bussu F. Synovial sarcoma of the parotid gland: A case report and review of the literature. Acta Otorhinolaryngologica Italica 2011 Feb;31(1):43-46.

6. Foreman SM, Stahl MJ. Biphasic synovial sarcoma in the cervical spine: Case report. Chiropractic Manual Therapies 2011;19:12.

7. Weiss SW, Goldblum J. Malignant soft tissue tumors of uncertain type. In: Weiss SW, Goldblum JR, editors. Enzinger and Weiss's soft tissue tumors. St. Louis (MO): CV Mosby; 2001. p. 1483-1571.

8. Reddy SD, Babu SA, Lenin A. Synovial sarcoma of larynx A rare site. Indian J Otolaryngol Head Neck Surg 2007 Mar;59(1):51-52.

9. Haleem AH, Imtiyaz H. Aggressive monophasic synovial sarcoma involving sublingual gland: First case. Natl J Maxillofac Surg 2013 Jul;4:239-241.

10. Tamarit JM, Navas PE, Ferriol EE, Galofre JD. Synovial sarcoma of the infratemporal fossa. Acta Otorrinolaringol Esp 2010 Sep;61(5):389-391. 